\title{
PENGEMBANGAN MODUL PUBLIC USERS PADA SISTEM INFORMASI KEARSIPAN AKADEMIK ELEKTRONIK (SIAMEL)
}

(Studi Action Research Pengembangan Modul Public Users Pada Sistem Informasi Kearsipan Akademik Elektronik (SiAMEL) Di Fakultas Ilmu Komunikasi Universitas Padjadjaran)

\author{
Kusnandar $^{1}$, Pawit M. Yusup ${ }^{2}$ \\ ${ }^{1,2}$ Program Studi Ilmu Perpustakaan Universitas Padjadjaran \\ ${ }^{1}$ kusnandar@unpad.ac.id, ${ }^{2}$ pawit.m.yusup@unpad.ac.id
}

\begin{abstract}
This research aims to know the needs of student information which can be met from SiAMEL. This research also aims to develop the database, and display the output from the application of the Public Users on SiAMEL module. The method used in this study is Action Research. Data collection techniques by way of observation, interview, note the field and study the literature. This research has resulted in the development of SiAMEL that can meet the needs of student information as Public Users among others: Data Lecturer, Data institution/ Institutions for MORNING, data proposed problem, as well as data about the schedule. Through this research has been done on the conversion some tables that are adjusted with the needs of the Public Users SiAMEL. In addition, page view early SiAMEL become open to public Users and changes to the navigation buttons (menu) SiAMEL. Some of the output SiAMEL changed some details that adjusted with the status of access authority SiAMEL, whether as administrator or as a Public Users.
\end{abstract}

Keywords: Public Users Modul, Archive Information System, SiAmel application

ABSTRAK - Penelitian ini bertujuan untuk mengetahui kebutuhan informasi mahasiswa yang dapat dipenuhi dari SiAMEL. Selain itu juga penelitian ini bertujuan untuk mengembangkan database, tampilan serta output dari aplikasi Modul Public Users pada SiAMEL. Metode yang digunakan pada penelitian ini adalah Action Research. Teknik pengumpulan data yaitu dengan cara observasi, wawancara, catatan lapangan, serta studi literatur. Penelitian ini telah menghasilkan pengembangan SiAMEL yang dapat memenuhi kebutuhan informasi mahasiswa sebagai Public Users antara lain: Data Dosen, Data Instansi/ Lembaga untuk PKL, data Usulan Masalah, serta data tentang Jadwal Sidang.
Melalui penelitian ini telah dilakukan pengubahan pada beberapa tabel yang disesuaikan dengan kebutuhan Public Users SiAMEL. Selain itu, tampilan halaman awal SiAMEL menjadi terbuka untuk Public Users serta perubahan pada navigasi (menu) SiAMEL. Beberapa output SiAMEL diubah beberapa detail yang disesuaikan dengan status otoritas akses SiAMEL, apakah sebagai Administrator atau sebagai Public Users.

Kata kunci: Modul Public Users, Sistem Informasi Kearsipan, aplikasi SiAmel

\section{PENDAHULUAN}

Sejak awal tahun 2012, pada Program Studi Ilmu Perpustakaan, Fakultas Ilmu Komunikasi Universitas Padjadjaran telah diterapkan aplikasi sistem informasi yaitu Sistem Informasi Kearsipan Akademik Elektronik (SiAMEL). Aplikasi tersebut merupakan prototipe yang dikembangkan melalui penelitian action research yang dilakukan oleh tim Peneliti pada akhir tahun 2011 dan telah dikembangkan kembali oleh tim Peneliti pada tahun 2012 sebagai bentuk penyempurnaan dari versi sebelumnya. Selama masa penerapannya, berdasarkan pra riset melalui wawancara dan observasi dengan staf administrasi Program Studi Ilmu Perpustakaan diperoleh gambaran bahwa SiAMEL terbukti cukup membantu penyelenggaraan kegiatan administrasi arsip akademik terutama dalam pembuatan SK Pembimbing, 
Surat Ijin Penelitian, Surat Ijin Praktek Kerja Lapangan (PKL), Surat Ijin Observasi, Surat Ijin Wawancara, Surat Ijin Magang dan pembuatan Surat Keterangan Masih Kuliah.

Meskipun SiAMEL sudah dianggap memberikan kontribusi dalam mendukung pengelolaan arsip akademik di Program Studi Ilmu Perpustakaan, SiAMEL hanya dapat diakses dan digunakan oleh staf administrasi. Padahal, beberapa data atau informasi yang terdapat pada SiAMEL dibutuhkan juga oleh mahasiswa. Misalnya, data tentang judul-judul Usulan Masalah yang terdapat dalam SiAMEL tidak bisa diakses secara langsung oleh mahasiswa. Untuk menentukan judul, mahasiswa membutuhkan pertimbangan, apakah judul yang dia akan ajukan sudah ada yang menggunakannya atau belum. Tentu saja kondisi ini perlu disikapi oleh staf administrasi Program Studi Ilmu Perpustakaan dalam rangka meningkatkan kualitas layanan akademik kepada mahasiswa.

Berdasarkan permasalahan di atas maka penelitian ini bermaksud untuk mengembangkan aplikasi Sistem Kearsipan Akademik Elektronik (SiAMEL) dengan melakukan penambahan fitur (modul) yang diperuntukkan bagi mahasiswa sebagai pengguna umum (Public Users). Dengan demikian, melalui penelitian ini diharapkan dapat mengembangkan SiAMEL sebagai aplikasi sistem kearsipan akademik elektronik yang selain dapat digunakan oleh staf administrasi tetapi juga dapat digunakan oleh mahasiswa sebagai bentuk upaya peningkatan kualitas layanan akademik di Program Studi Ilmu Perpustakaan, Fakultas Ilmu Komunikasi, Universitas Padjadjaran. Hasil yang ingin dicapai dalam penelitian ini adalah:
1. Untuk mengetahui kebutuhan informasi mahasiswa yang dapat dipenuhi dari SiAMEL.

2. Untuk membuat rancangan pengembangan database Modul Public Users pada SiAMEL.

3. Untuk membuat rancangan pengembangan tampilan aplikasi Modul Public Users pada SiAMEL.

4. Untuk membuat rancangan pengembangan output aplikasi Modul Public Users pada SiAMEL.

\section{TINJAUAN PUSTAKA}

Menurut Peraturan Menteri Pendidikan Nasional Republik Indonesia No. 37 Tahun 2006 tentang Tata Kearsipan di Lingkungan Departemen Pendidikan Nasional, arsip elektronik adalah arsip yang diciptakan, digunakan, dan dipelihara sebagai bukti transaksi, aktivitas dan fungsi lembaga atau individu yang ditransfer dan diolah dengan sistem komputer.

Sementara itu, The California Department of General Services (DGS), State Records (2002, 3) mendefinisikan arsip elektronik sebagai berikut:

"Electronic records are informational or data files that are created and stored in digitized form through the use of computers and applications software. They are stored on various magnetic and optical storage devices and are products of computers and computer software."

Arsip elektronik merupakan segala bentuk file yang diciptakan dan disimpan dalam bentuk dijital 
dengan penggunaan komputer dan perangkat lunak aplikasi. Dengan kata lain, setiap aktivitas organisasi yang menghasilkan suatu bentuk file (teks, suara, gambar, film) dengan menggunakan komputer (teknologi informasi) dalam rangka penyelenggaraan aktivitas organisasi, maka file tersebut dikategorikan sebagai arsip elektronik.

Penerapan teknologi informasi dan komunikasi lebih terasa manfaatnya terutama dalam hal pemberdayaan arsip dalam bentuk aktivitas penelusuran kembali arsip. Kemampuan dari sebuah program komputer dalam menemukan kembali suatu arsip yang dicocokkan dengan kata kunci pencarian sangatlah handal. Apalagi, jika program tersebut didukung oleh database yang disusun secara baik maka tingkat kemampuan pencarian dari teknologi tersebut semakin meningkat. Dalam hal ini, Amsyah menyatakan:

"Untuk mempercepat penemuan kembali arsip yang berada dalam kumpulan jumlah arsip yang besar, baik yang baru tersimpan maupun yang sudah tersimpan lama, penggunaan komputer sangat membantu. Komputer dapat menyimpan seluruh tulisan yang terdapat pada suatu dokumen secara lengkap, atau penyimpanan data-data dasarnya saja, tergantung kepada kebutuhan dan kemampuan komputer yang dipergunakan”. (Amsyah 2001, 222)

Karena peralatan dan arsip yang digunakan dalam sistem penelusuran sangat kompleks dan beragam, beberapa hal perlu diperhatikan dalam perancangan dan pengoperasian sistem penelusuran. Karena itu, penerapan sistem penelusuran mekanistis (berbasis komputer) dalam sistem kearsipan perlu mempertimbangkan hal-hal berikut ini (Johnson dan Kallaus 1982, 281):

1. Kondisi terkini dari jumlah atau ukuran file yang ada; tingkat pertumbuhannya, berapa banyak penambahan yang diperkirakan di masa mendatang.

2. Apakah sistem digunakan untuk menelusur informasi berdasarkan subjek: untuk menemukan orang, tempat, atau sesuatu berdasarkan kriteria yang sudah jelas; atau untuk menemukan nomor kode yang digunakan untuk menggambarkan setiap file yang dimasukkan ke dalam sistem.

3. Bentuk fisik, format, biaya dan sumber daya untuk memasukkan data ke dalam sistem dan output yang diharapkan oleh pengguna sistem.

4. Berapa banyak dokumen atau data yang akan berubah, diperbaharui, dimusnahkan/ dihapus, serta seberapa sering perubahan tersebut terjadi.

5. Jumlah rata-rata istilah indeks yang digunakan untuk mencari arsip dan jumlah rata-rata file yang diperkirakan akan dicari setiap harinya.

6. Perkiraan rata-rata beban kerja, titik tertinggi dan titik terendah beban kerja.

7. Jumlah dan jenis orang yang menggunakan sistem penelusuran dan keberadaan lokasi mereka di wilayah perusahaan.

8. Tingkat kecepatan yang diperlukan dalam penyajian arsip.

9. Tingkat akurasi dan reliabilitas atas suatu permintaan arsip. 
10. Sumber daya, termasuk modal, personalia/ petugas, dan peralatan yang disediakan untuk menjalankan sistem.

\section{METODE PENELITIAN}

Metode yang digunakan dalam penelitian ini adalah Action Research atau biasa juga disebut Penelitian Tindakan. Metode ini digunakan untuk menganalisis suatu permasalahan serta menemukan solusi atas masalah tersebut. "Penelitian tindakan adalah cara melakukan penelitian dan berupaya bekerja untuk memecahkan masalah pada saat yang bersamaan" (Cormack 1991 dalam Moleong 2007, 238).

Dalam bidang sistem informasi, metodologi yang termasuk ke dalam kelompok Action Research, antara lain: Cannonical, IS Prototyping, Soft Systems Methodology, ETHICS, Action Science, Participant Observation, Action Learning, Multiview, Clinical Field Work, dan Process Consultation. Penelitian ini menggunakan Metode prototype yaitu suatu teknik analisis dan rancangan yang memungkinkan pemakai ikut serta dalam menentukan kebutuhan dan pembentukan sistem apa yang akan dikerjakan untuk memenuhi kebutuhan tersebut. Langkah umum paradigma prototyping adalah sebagai berikut:

a. Mengidentifikasi kebutuhan pemakai.

b. Merancang prototype.

c. Menentukan apakah prototype dapat diterima oleh pemakai.

d. Mengadakan sistem operasional.

e. Menguji sistem operasional.

f. Menentukan sistem operasional g. Jika sistem telah disetujui, maka tahap terakhir adalah melakukan implementasi sistem.

\section{HASIL DAN PEMBAHASAN}

Pengembangan SiAMEL pada penelitian ini dilatarbelakangi oleh pandangan peneliti bahwa sebagai sebuah sistem penunjang kegiatan akademik di Program Studi Ilmu Informasi dan Perpustakaan Fakultas Ilmu Komunikasi, SiAMEL seharusnya dapat membantu proses layanan akademik secara optimal. Selama ini, pelayanan akademik berbasis SiAMEL masih terbatas penggunaannya hanya oleh administrator. Dengan kata lain, mahasiswa sebagai objek layanan akademik, belum bisa memanfaatkan SiAMEL secara langsung. Administrator SiAMEL, masih diperlukan kehadirannya $100 \%$ dalam melayani kebutuhan akademik mahasiswa. Padahal, berdasarkan pengamatan peneliti terhadap data yang tersimpan dalam database pada SiAMEL, ada beberapa data yang sebetulnya bisa diakses langsung oleh mahasiswa melalui SiAMEL tanpa bantuan atau keterlibatan administrator. Sebagai contoh, untuk sekedar tahu data tentang judul apa saja yang pernah diusulkan dalam Usulan Masalah, mahasiswa tentunya bisa menggunakan SiAMEL untuk melakukan penelusuran informasi mengenai hal tersebut. Sayangnya, saat ini, SiAMEL belum dapat digunakan seperti itu. Mahasiswa harus bertanya kepada administrator terlebih dahulu. Setelah itu, barulah administrator melakukan penelusuran informasi dan membantu mahasiswa menemukan jawabannya. Tentunya, kondisi seperti ini menunjukkan bahwa SiAMEL masih belum optimal fungsinya sebagai sebuah sistem yang menunjang kegiatan layanan akademik. Oleh 
karena itu, SiAMEL perlu dikembangkan fungsinya agar dapat digunakan oleh mahasiswa sebagai pengguna umum SiAMEL atau yang disebut dengan istilah Public Users.

Berdasarkan hasil penelitian tentang kebutuhan informasi mahasiswa sebagai Public Users di atas, diperoleh data bahwa ada beberapa hal yang menjadi perhatian peneliti untuk kemudian ditindaklanjuti pada tahap penelitian berikutnya yaitu:

1. Mahasiswa membutuhkan data Dosen setidaknya untuk kepentingan pelaporan dan komunikasi.

2. Mahasiswa membutuhkan data Instansi/ Lembaga yang mereka bisa jadikan tempat untuk PKL.

3. Mahasiswa membutuhkan informasi tentang Jadwal Sidang Usulan Masalah atau mungkin juga untuk jadwal sidang lainnya, seperti Jadwal Sidang Komprehensif dan Jadwal Sidang Skripsi.

4. Mahasiswa dapat melakukan penelusuran secara mandiri melalui SiAMEL untuk data Usulan Masalah yang bisa dijadikan pembanding agar terhindar dari duplikasi penelitian.

5. Untuk data yang berkaitan dengan layanan akademik pada SiAMEL seperti data Usulan Masalah, data pengajuan PKL, Izin Wawancara, Izin Observasi, Izin Penelitian, serta Surat Keterangan Masih Kuliah juga sangat dimungkinkan untuk dikembangkan agar bisa diinput langsung oleh mahasiswa sehingga dapat meringankan pekerjaan administrator.
Setelah menganalisis kebutuhan informasi mahasiswa, peneliti selanjutnya melakukan penyesuaian beberapa konsep tabel yang ada pada database SiAMEL. Tabel tersebut yakni yang berhubungan dengan Data Dosen dan Data Jadwal Sidang. Data Dosen yang terdapat pada tabel "tbl_dosen" saat ini belum memenuhi kebutuhan informasi minimal yang dibutuhkan oleh mahasiswa sebagai Public Users. Sementara itu, untuk kepentingan Data Jadwal Sidang, SiAMEL versi sebelumnya belum menyediakan data tersebut. Oleh karena itu, pada penelitian ini, perlu ditambahkan tabel baru untuk menyimpan Data Jadwal Sidang.

Pada penelitian ini, pengembangan SiAMEL berkaitan dengan kepentingan mahasiswa untuk mengakses data yang terdapat pada SiAMEL. Oleh karena itu, agar SiAMEL juga dapat digunakan oleh mahasiswa, maka tahap selanjutnya peneliti melakukan beberapa perubahan tampilan aplikasi SiAMEL. Perubahan tampilan ini meliputi halaman utama SiAMEL, menu SiAMEL, serta beberapa perbedaan tampilan Public Users dengan tampilan Administrator. Tampilan awal ketika aplikasi SiAMEL dibuka. Tampilan awal pada SiAMEL versi sebelumnya menyediakan Log In khusus untuk Administrator.

Langkah berikutnya setelah melakukan pengembangan tampilan aplikasi SiAMEL, peneliti melakukan pengembangan output aplikasi Modul Public Users. Adapun output aplikasi SiAMEL pada penelitian ini terkait langsung dengan perubahan tabel pada database, yakni tabel dosen ("tbl_dosen") dan tabel Jadwal Sidang ("tbl_jadsidang"). Sementara output yang terkait 
data lainnya sama atau tidak mengalami perubahan signifikan. Secara keseluruhan, perubahan output yang terjadi pada SiAMEL melalui penelitian ini adalah bahwa data yang terdapat pada aplikasi SiAMEL dapat diakses oleh mahasiswa sebagai Public Users (sebelumnya hanya Administrator SiAMEL yang bisa mengakses data pada SiAMEL).

\section{SIMPULAN}

1. Kebutuhan informasi mahasiswa sebagai Public Users yang dapat dipenuhi dari SiAMEL antara lain: Data Dosen, data Instansi/ Lembaga untuk PKL, data Usulan Masalah, serta data tentang Jadwal Sidang (Usulan Masalah, Sidang Komprehensif dan Jadwal Sidang Skripsi).

2. Melalui penelitian ini telah dilakukan pengubahan beberapa tabel yang disesuaikan dengan kebutuhan Public Users SiAMEL. Adapun tabel yang diubah adalah tabel yang berisi Data Dosen yang diberi nama "tbl_dosen" serta tabel yang berisi data Jadwal Sidang yang diberi nama "tbl_jadsidang".

3. Tampilan SiAMEL diubah dari yang sebelumnya menampilkan halaman Log In menjadi terbuka. Halaman Log In masih tetap disediakan, namun terbatas untuk administrator SiAMEL saja. Termasuk perubahan yang dilakukan juga dalam hal navigasi (menu) SiAMEL.

4. Beberapa output data pada halaman website SiAMEL diubah beberapa detail yang disesuaikan dengan status otoritas akses
SiAMEL, apakah sebagai Administrator atau sebagai Public Users.

\section{DAFTAR PUSTAKA}

Amsyah, Zulkifli. (2001). Manajemen Kearsipan. Jakarta: Gramedia Pustaka Utama.

Johnson, Mina M. dan Kallaus, Norman F. (1982). Records Management. Cincinnati, Ohio: South-Western Publishing.

Moleong, Lexy J. (2007). Metodologi Penelitian Kualitatif. Bandung: Remaja Rosdakarya.

Republik Indonesia. Undang-undang No. 7 Tahun 1971 tentang Ketentuan-ketentuan Pokok Kearsipan.

Republik Indonesia. Peraturan Menteri Pendidikan Nasional Republik Indonesia Nomor 37 Tahun 2006 tentang Tata Kearsipan di Lingkungan Departemen Pendidikan Nasional.

Baskerville, Richard L. (1999). Investigating Information Systems with Action Research. Communications of the Association for Information Systems 2(19). Diakses dari: http://cis.gsu.edu/ rbaskerv/CAIS_2_19/cai s_2_19.pdfDiakses tanggal: 12-11-2011.

Government of Alberta. (2005). Naming Conventions for Electronic Documents. Alberta, Canada: Information Management, Branch Government and Program Support Services Alberta Government Services. Diakses dari: https://www.rimp.gov.ab.ca/publications/pd f/documentnamingconventions.pdf. Diakses tanggal: 30-03-2012.

Krishnaveni, R. dan Meenakumari, J. (2010). Usage of ICT for Information Administration in Higher education Institutions - A study. International Journal of Environmental Science and Development, Vol. 1, No. 3, August 2010. Diakses dari: http://www.ijesd.org/papers/55-D461.pdf. Diakses tanggal: 10-04-2012. 
State Records Department of General Service State of California. (2002). Electronic Records Management Handbook. Sacramento, California: California Records and Information Management (Calrim). Diakses dari: http://www.documents.dgs.ca.gov/osp/recs/e rmhbkall.pdf. Diakses tanggal: 04-04-2012. 
